\title{
Resource-Based View as a Competitive Advantage of the Company: an Empirical Review
}

\author{
Heru Basuki Purwanto \\ Management Science Study of Graduate School Program \\ Universitas Pendidikan Indonesia \\ herbas76@student.upi.edu
}

\begin{abstract}
Strategy is the fit between the firm's external condition and its internal capabilities. Significant changes in the external condition will affect the changes of the company's internal condition such as the resources and the capabilities, and the organization in order to realign the company could keep-up with its environment. The Resource Based View helps us to understand how firms achieve and sustain their competitiveness through resource building as well as leveraging it. This study aims to determine the company's bundle of resources that influence growth. According to the RBV, only the 'Value, Rareness, Imitability and Organization (VRIO), that possessed by the company can create capabilities and uniqueness to ensure profits and improve the performance of the company. A company is said to have a sustainable competitiveness, if it performs more cost efficient than its competitors.
\end{abstract}

Keywords - RBV, VRIO, sustainable competitiveness

\section{INTRODUCTION}

Changes the dynamic corporate environment has changed the overall interests and strategies adopted by the company. Earlier, more attention is given to the circumstances that occurred outside the company either in the form of environmental change or in competition among existing industry players. In its development, it no longer only focused attention to conditions outside the company, but also within the company. Changes within the company, could be done by readjustment of the existence of the resources possessed by the company, the company's organizational transformation and upgrade its competence on their human resources to meet the demands of the existing competition, known as the Resource Based View (RBV). Approach via the resourcebased view has been considered better for the company in the face of competition in the industry than if merely by adapting the changes that occur outside the company [1].

\section{RBV As COMPETITIVE AdVANTAGE}

Resource Based View is a method to review the resources of the company through the evaluation, selection and integration with the aim to obtain maximum results. Interest $\mathrm{RBV}$ is to find forms of business process most efficient, according to the needs of the company. With efficient business process, companies can reduce costs as optimal as possible, which can further improve their performance and at the end will eventually be able to improve its competitiveness.
Company resources can be classified into three parts. The first part is tangible resources, such as plants, equipment, locations, and finance. The second part is intangible resources, such as patents, copyrights, culture, and reputation. And the third part is human resources, such as employees, skill, and motivation [2]. RBV is a company's ability of how to manage those three resources integrately, so that it produces a big opportunity to the company's competitive advantage [3]. If these resources can be managed well through a good business processes, then it will result the increase of the company's capability. The ability to manage the existing resources in various functions of the company and then integrate it together to produce a larger capability, it's known as competency. For example, with a good cooperation among those functions, such as marketing, sales, and production as well as good information support system, a company can be assured to produce much better products with better quality. If such competencies are spread-out in various existing divisions within the company and the company can offer the products that do not only have high quality, but are also favored by the customers because of their affordability prices, than those competencies are called as core competencies. The objective of RBV is not only about achieving the preparation of resources, capabilities, and competencies internally, but also about how all those possessed competencies become the key strengths of the company to compete in the industry. Therefore, been always updated with the changes in the industry, that was becoming very important and crucial things to the products always be fitted with the customers want and need [4]. Core competencies that are appropriate to the changes are called distinctive competencies that supported by such a good dynamic capability in the company's environment [5].

Although distinctive competency can be considered as a key strength of the company, but not all of this company's strengths become the distinctive competency. In this very tight competition era, competitors always observe and analyze the powers constellation between each existing players. Imitating will always happen for sure. Once our products can be imitated, the distinctive competency we have will decrease or even not exist anymore. For example, Apple is well known for their functional design ability. The iPod, iPad, and mostly the iPhone are examples of their distinctive competency. As other phone manufacturers (in particular) imitated Apple's designs and released ever more stylish phones, we would say that this 


\section{A trantse PRESS}

continued to be a key strength (that is, a core competency) of Apple, but it was less and less a distinctive competency [2].
All processes and relationships among those various factors, then could be constructed in one integrated building blocks as seen in Figure 1:

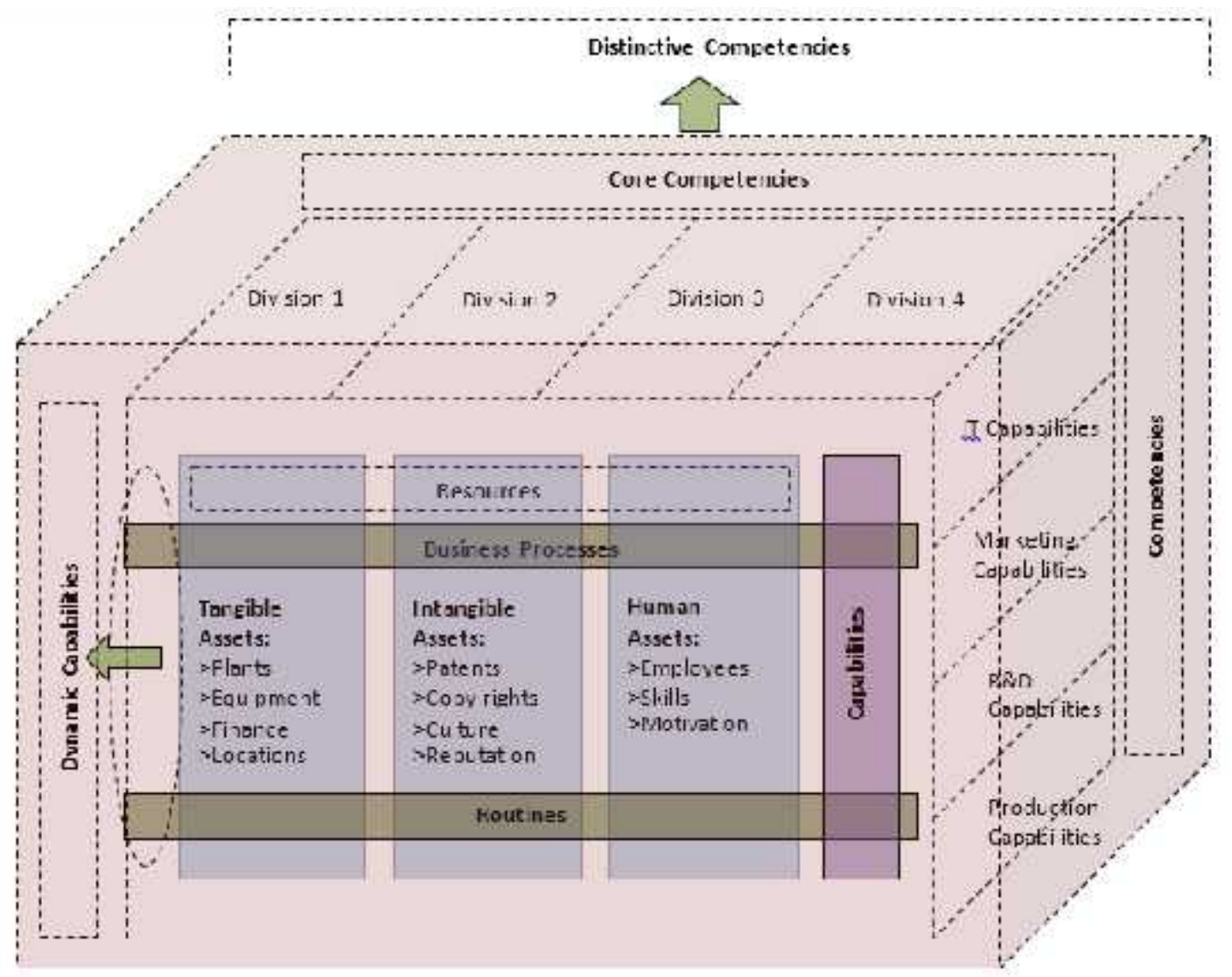

Fig. 1. RBV's Building-Blocks

\section{METHODOLOGY}

In order to understand the RBV either ready or not, we can do the following procedures:

1) Company's performance evaluation

2) Review the company's value chain system

3) Doing the VRIO analysis: Value, Rareness, Imitability and Organization

By understanding the comparison of the company's current performance conditions and the previous one, we will know what was really experienced by the company during the period observed. Also, we are able to identify the trend of the industry's environment. This should be the most important steps to analyze the position of the company where it stands at that moment and at the same time we will know where the company's direction will be taken. Once the company's direction has been taken, then a guideline about how to implement it. By a complete review over the value chain system of the company's business processes, we will be able to identify what were the strengths and weaknesses of the company compared to those of the competitors in the industry [2], [6]. Finally, by doing the analysis the VRIO approach, then we would find out the uniqueness of the product

\section{ANALYSIS}

\section{A. Company Performance}

By producing such a unique shoe, the customer segment has been created also become segmented. But when it is reviewed from the company's sales and net profit achievement year to year, the company has a very good financial performance. This proves that the company can survive, the production process going very well, and the company continues to enjoy their captive market with the very loyal customers [3].

\section{B. Value Chain System}

We take an example of a leather shoemaker company. As we know that the process start with the leather ordered first as a raw material of the shoes, and then followed by designing the model of the shoes and the next step was shoe making process by the shoemakers until finished as a pair of shoes 
ready to wear. After that, the shoes would be stored in the warehouse first before send it to the market. In order to enter into the marketplace, the marketing person will prepare all the things needed before distributing it, such as pricing and promotion policy. Once the product is on the market, the service division starts to do their jobs. All of those shoe making processes describe above could be seen systematically in Figure 2.

From the illustration above, we can identify that the key process to produce the shoe is on the importing of the leather as a raw material and the existence of the shoemaker. The importing process occurs in the inbound logistics node, while the shoemaker existence is in the operation process node.
How is the quality of the leather? Is it already appropriated with the requirement or not? When will it arrive? Is it arrived on time or not? If all those things can be fulfilled, then the next processes could be continued well. The next step is operation process, where the shoemaker plays its role. Do their skills still fit to the current needs? Are they always available? Those factors will really determine the end result of the shoe making process. Then, how about the roles of the other value chain steps, such as outbound logistics, marketing \& sales, and services? Of course they have a very important role, but not as key processes in this case. From the analysis above, then it can be identified that the key processes are inbound logistics and operations steps that will influence the whole process of the products [2].

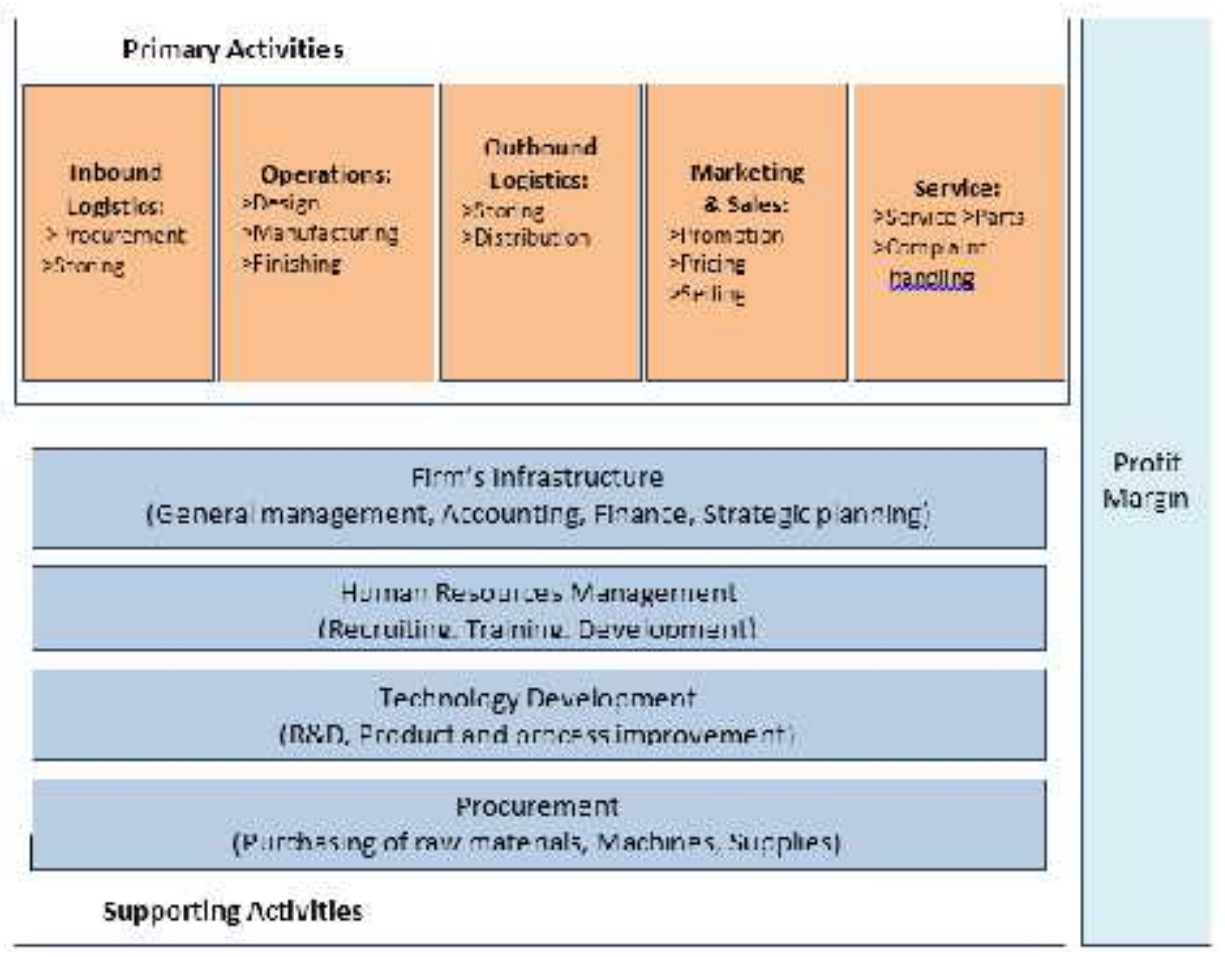

Source: (Wheelen \& Hunger, p 169. 2015)

Fig. 2. Value Change System

\section{VRIO}

How could we review by using the VRIO framework? It could be explained as follows [7].

\section{Value}

The question of value is: "Do resources and capabilities enable a firm to exploit an external opportunity or neutralize an external threat?" If a firm answers this question with a "yes," then its resources and capabilities are valuable and can be considered strengths. If a firm answers this question with a "no," its resources and capabilities are weaknesses. There is nothing inherently valuable about a firm's resources and capabilities. Rather, they are only valuable to the extent that they enable a firm to enhance its competitive position. Sometimes, the same resources and capabilities can be strengths in one market and weaknesses in another [8].

The shoes produced by the company are unique, comfortable, and have a good quality, but still at affordable prices. Therefore, these shoes are favored by the customers. That is mean, the shoes have high value compared to the other similar products in the market.

\section{Rareness}

The Question of Rarity. Is a resource currently controlled by only a small number of competing firms? Understanding the value of a firm's resources and capabilities is an important first consideration in understanding a firm's internal strengths and weaknesses. However, if a particular resource or capability is controlled by numerous competing firms, then 
that resource is unlikely to be a source of competitive advantage for any one of them. Instead, valuable but common (i.e., not rare) resources and capabilities are sources of competitive parity. Only when a resource is not controlled by numerous other firms is it likely to be a source of competitive advantage. These observations lead to the question of rarity: "How many competing firms already possess particular valuable resources and capabilities?" Consider, for example, competition among television sports channels. All the major networks broadcast sports. In addition, several sports-only cable channels are available, including the best-known allsports channel, ESPN. Several years ago, ESPN began televising what were then called alternative sportsskateboarding, snowboarding, mountain biking, and so forth. The surprising popularity of these programs led ESPN to package them into an annual competition called the " $\mathrm{X}$ Games." "X" stands for "extreme," and ESPN has definitely gone to the extreme in including sports in the X-Games. The $\mathrm{X}$-Games have included sports such as sky-surfing, competitive high diving, competitive bungee cord jumping, and so forth. ESPN broadcasts both a summer X-Games and a winter X-Games. No other sports outlet has yet made such a commitment to so-called extreme sports, and it has paid handsome dividends for ESPN-extreme sports have very low-cost broadcast rights and draw a fairly large audience. This commitment to extreme sports-as an example of a valuable and rare capability - has been a source of at least a temporary competitive advantage for ESPN. Of course, not all of a firm's resources and capabilities have to be valuable and rare. Indeed, most firms have a resource base that is composed primarily of valuable but common resources and capabilities. These resources cannot be sources of even temporary competitive advantage, but are essential if a firm is to gain competitive parity. Under conditions of competitive parity, although no one firm gains a competitive advantage, firms do increase their probability of survival. How rare a valuable resource or capability must be in order to have the potential for generating a competitive advantage varies from situation to situation. It is not difficult to see that, if a firm's valuable resources and capabilities are absolutely unique among a set of current and potential competitors, they can generate a competitive advantage. However, it may be possible for a small number of firms in an industry to possess a particular valuable resource or capability and still obtain a competitive advantage. In general, as long as the number of firms that possess a particular valuable resource or capability is less than the number of firms needed to generate perfect competition dynamics in an industry, that resource or capability can be considered rare and a potential source of competitive advantage [8].

By using specific raw material and with a specific shoe design, these shoes become rare and hunted by their customers.

\section{Imitability}

The Question of Imitability. Do firms without a resource face a cost disadvantage in obtaining or developing it? Firms with valuable and rare resources are often strategic innovators because they are able to conceive and engage in strategies that other firms cannot because they lack the relevant resources and capabilities. These firms may gain the first-mover advantages. Valuable and rare organizational resources, however, can be sources of sustained competitive advantage only if firms that do not possess them face a cost disadvantage in obtaining or developing them, compared to firms that already possess them. These kinds of resources are imperfectly imitable. These observations lead to the question of imitability: "Do firms without a resource or capability face a cost disadvantage in obtaining or developing it compared to firms that already possess it?"

Imagine an industry with five essentially identical firms. Each of these firms manufactures the same products, uses the same raw materials, and sells the products to the same customers through the same distribution channels. It is not hard to see that firms in this kind of industry will have normal economic performance. Now, suppose that one of these firms, for whatever reason, discovers or develops a heretofore unrecognized valuable resource and uses that resource either to exploit an external opportunity or to neutralize an external threat. Obviously, this firm will gain a competitive advantage over the others. This firm's competitors can respond to this competitive advantage in at least two ways. First, they can ignore the success of this one firm and continue as before.

This action, of course, will put them at a competitive disadvantage. Second, these firms can attempt to understand why this one firm is able to be successful and then duplicate its resources to implement a similar strategy. If competitors have no cost disadvantages in acquiring or developing the needed resources, then this imitative approach will generate competitive parity in the industry. Sometimes, however, for reasons that will be discussed later, competing firms may face an important cost disadvantage in duplicating a successful firm's valuable resources. If this is the case, this one innovative firm may gain a sustained competitive advantagean advantage that is not competed away through strategic imitation. Firms that possess and exploit costly-to-imitate, rare, and valuable resources in choosing and implementing their strategies may enjoy a period of sustained competitive advantage. For example, other sports networks have observed the success of ESPN's X-Games and are beginning to broadcast similar competitions. NBC, for example, developed its own version of the X-Games, called the "Gravity Games," and even the Olympics now include sports that were previously perceived as being "too extreme" for this mainline sports competition. Several Fox sports channels broadcast programs that feature extreme sports, and at least one new cable channel (Fuel) broadcasts only extreme sports. Fuel was recently acquired by Fox to provide another outlet for extreme sports on a Fox channel. Whether these efforts will be able to attract the competitors that the X-Games attract, whether winners at these other competitions will gain as much status in their sports as do winners of the X-Games, and whether these other competitions and programs will gain the reputation among viewers enjoyed by ESPN will go a long way to determining whether ESPN's competitive advantage in extreme sports is temporary or sustained [8]. 
These shoes are made of specific leather which is ordered and manufactured by experts, so that's why this shoe becomes hard to be imitated.

\section{Organization}

The Question of Organization. Are a firm's other policies and procedures organized to support the exploitation of its valuable, rare, and costly-to-imitate resources? A firm's potential for competitive advantage depends on the value, rarity, and imitability of its resources and capabilities. However, to fully realize this potential, a firm must be organized to exploit its resources and capabilities. These observations lead to the question of organization: "Is a firm organized to exploit the full competitive potential of its resources and capabilities?" Numerous components of a firm's organization are relevant to the question of organization, including its formal reporting structure, its formal and informal management control systems, and its compensation policies. A firm's formal reporting structure is a description of whom in the organization reports to whom; it is often embodied in a firm's organizational chart. Management control systems include a range of formal and informal mechanisms to ensure that managers are behaving in ways consistent with a firm's strategies. Formal management controls include a firm's budgeting and reporting activities that keep people higher up in a firm's organizational chart informed about the actions taken by people lower down in a firm's organizational chart. Informal management controls might include a firm's culture and the willingness of employees to monitor each other's behavior. Compensation policies are the ways that firms pay employees. Such policies create incentives for employees to behave in certain ways. These components of a firm's organization are often called complementary resources and capabilities because they have limited ability to generate competitive advantage in isolation. However, in combination with other resources and capabilities they can enable a firm to realize its full potential for competitive advantage. For example, it has already been suggested that ESPN may have a sustained competitive advantage in the extreme sports segment of the sports broadcasting industry. However, if ESPN's management had not taken advantage of its opportunities in extreme sports by expanding coverage, ensuring that the best competitors come to ESPN competitions, adding additional competitions, and changing up older competitions, then its potential for competitive advantage would not have been fully realized. Of course, the reason that ESPN has done all these things is because it has an appropriate organizational structure, management controls, and employee compensation policies. By themselves, these attributes of ESPN's organization could not be a source of competitive advantage; however, they were essential for ESPN to realize its full competitive advantage potential. Having an appropriate organization in place has enabled ESPN to realize the full competitive advantage potential of its other resources and capabilities. Having an inappropriate organization in place prevented Sony from exploiting its valuable, rare, and costly-to-imitate resources and capabilities.[8]

To produce its shoes, the company applied such a specific organization and management system by offering a special reward system to the shoemaker to engage and retain their best employees stay with the company. By using this special treatment, the company could maintain the efficiency of the whole process of the company on the most effective way.

\section{CONCLUSION}

By using RBV and VRIO analysis approach, the company can evaluate and optimize their resources to achieve their maximum capability, competency, and dynamic capabilities that will lead the company be able to adapt the changes and maintain the uniqueness as their distinctive competencies. The strategy that could to be applied is by maintaining and preserving the core competencies that become the key strengths of the company to stay keep-up in the industry.

\section{LIMITATION OF STUDY}

Because a size of the company, which is a small company, single business with a simple business process, and also the uniqueness of the product produced, therefore the review and analysis has been conducted are limited due to the limitation of the data and information available.

\section{REFERENCES}

[1] J. Andersén, "Resource-based competitiveness: Managerial implications of the resource-based view," Strateg. Dir., vol. 26, no. 5, pp. 3-5, 2010.

[2] T. L. Wheelen and J. D. Hunger, Strategic Management and Business Policy Globalozation, Innovation and Sustainability, 14th Editi. London: Pearson Education Limited, 2015.

[3] G. Azzone, U. Bertelè, and A. Rangone, "Measuring resources for supporting resource-based competition," Manag. Decis., vol. 33, no. 9, pp. 57-62, 1995.

[4] K. Chaharbaghi and R. Lynch, "Sustainable competitive advantage: towards a dynamic resource-based strategy," Manag. Decis., vol. 37(1), pp. 45-50, 1999.

[5] V. Clulow, J. Gerstman, and C. Barry, "The resource-based view and sustainable competitive advantage: the case of a financial services firm," J. Eur. Ind. Train., vol. 27, no. 5, pp. 220-232, 2003.

[6] M. Bourne, J. Mills, and N. Faull, "Operations strategy and performance: a resource-based perspective.," Int. J. Oper. Prod. Manag., vol. 23, p. 944, 2003.

[7] C. Lin, "A fuzzy quantitative VRIO-based framework for evaluating organizational activities," Manag. Decis., vol. 50, no. 8, pp. 1396-1411, 2012.

[8] J. B. B. and W. S. Hesterly, trategic Management and Competitive Advantage Concepts and Cases, Global Edi. London: Pearson Education Limited, 2015. 